\title{
Comparison of Crystallization Rate and Macroscopic Morphology of Two Oxyethylene/Oxybutylene Triblock Copolymers. The Effect of Molecular Architecture
}

\author{
Junting $\mathrm{XU},{ }^{\dagger}$ Guodong LIANG, and Zhiqiang FAN \\ Department of Polymer Science \& Engineering, Zhejiang University, Hangzhou 310027, China
}

(Received October 29, 2003; Accepted April 5, 2004; Published June 15, 2004)

\begin{abstract}
Two oxyethylene/oxybutylene triblock copolymers, $\mathrm{B}_{28} \mathrm{E}_{182} \mathrm{~B}_{28}$ and $\mathrm{E}_{91} \mathrm{~B}_{56} \mathrm{E}_{91}$, which have the same chain length and segregation strength but different architectures, were selected for characterization and the effect of architecture on crystallization rate and macroscopic morphology was investigated. It is found that these two triblock copolymers have similar melting temperatures and the same long periods both in the solid and in the melt. However, the crystallization temperature of $\mathrm{E}_{91} \mathrm{~B}_{56} \mathrm{E}_{91}$ is more easily affected by the cooling rate in non-isothermal crystallization and $\mathrm{E}_{91} \mathrm{~B}_{56} \mathrm{E}_{91}$ exhibits slower crystallization rate than $\mathrm{B}_{28} \mathrm{E}_{182} \mathrm{~B}_{28}$ in isothermal crystallization. A novel macroscopic morphology that the frontier of crystallization zones and that of spherulites are mutually different is observed by polarized optical microscopy in $\mathrm{E}_{91} \mathrm{~B}_{56} \mathrm{E}_{91}$, whereas these two frontiers are identical for $\mathrm{B}_{28} \mathrm{E}_{182} \mathrm{~B}_{28}$. The slower crystallization rate and poorer ability of organization into spherulite of $\mathrm{E}_{91} \mathrm{~B}_{56} \mathrm{E}_{91}$ are attributed to the difficulty in conformational change of the amorphous B block during crystallization since both ends of the B block are immobilized at the interface. [DOI 10.1295/polymj.36.465]

KEY WORDS Crystallization / Block Copolymers / Morphology / Microstructure /
\end{abstract}

In triblock copolymers, the connection sequence of the different blocks has a great influence on the properties of the triblock copolymers. For example, two $A_{n / 2} B_{m} A_{n / 2}$ and $B_{m / 2} A_{n} B_{m / 2}$ triblock copolymers have the same composition and chain length (i.e. the same segregation strength), but have different orderdisorder transition temperatures $\left(T_{\mathrm{ODT}}\right),{ }^{1,2}$ because the stretching energy of the blocks varies with the position (The middle block usually has lower stretching energy than the end block since its two block-junctions are located at the interface of the two blocks.). ${ }^{3}$ Moreover, theoretical analysis and experimental data show that the phase diagrams of $A_{n / 2} B_{m} A_{n / 2}$ and $B_{m / 2} A_{n} B_{m / 2}$ triblock copolymers are asymmetric. ${ }^{2-6}$ The architecture also affects the solution properties of triblock copolymer. In the presence of selective solvent for the A block, coupling between different micelles may occur in $B_{m / 2} A_{n} B_{m / 2}$ triblock copolymer, but this does not happen in $A_{n / 2} B_{m} A_{n / 2}$ triblock copolymer. ${ }^{7,8}$

The structures of oxyethylene/oxybutylene diblock and triblock copolymers (represented by $\mathrm{E}_{\mathrm{m}} \mathrm{B}_{\mathrm{n}}$, $B_{n / 2} E_{m} B_{n / 2}$ and $E_{m / 2} B_{n} E_{m / 2}$, where $E$ is oxyethylene unit and $\mathrm{B}$ is oxybutylene unit) in the melt and in the solid state have been systematically compared in terms of the overall length of the block copolymer and the length of single E block. ${ }^{2,4,9}$ It has been shown that $B_{n / 2} E_{m} B_{n / 2}$ and $E_{m / 2} B_{n} E_{m / 2}$ triblock copolymers have similar structure including long period and melting temperature, though their order-disorder transition temperatures are different. ${ }^{2,4,9}$ However, in $B_{n / 2} E_{m}$ $\mathrm{B}_{\mathrm{n} / 2}$ triblock copolymer the central crystallizable $\mathrm{E}$ block is connected with amorphous B block at both ends of the $E$ block, whereas in $E_{m / 2} B_{n} E_{m / 2}$ both ends of the amorphous B block are immobilized at the interface when crystallized from micro-phase separated state. Since both the B block and the E block change their conformation during crystallization, crystallization of the E block is inevitably affected by the amorphous B block. We believe that the block copolymer has different mobility when the segments are connected in different ways, which may affect crystallization kinetics and the ability of organization into spherulite. To our best knowledge, there are few reports on the effect of architecture of triblock copolymer on crystallization kinetics. Moreover, the macroscopic morphologies of triblock copolymers with different architectures are rarely compared in literature. In the present work, we selected two oxyethylene/oxybutylene triblock copolymers, $\mathrm{B}_{28} \mathrm{E}_{182} \mathrm{~B}_{28}$ and $\mathrm{E}_{91} \mathrm{~B}_{56} \mathrm{E}_{91}$, which have exactly the same chain length, and the crystallization process and macroscopic morphology of these two triblock copolymers were compared.

\section{EXPERIMENTAL}

\section{Materials}

The synthesis and characterization of oxyethylene/ oxybutylene triblock copolymers $\mathrm{B}_{28} \mathrm{E}_{182} \mathrm{~B}_{28}$ and $\mathrm{E}_{91} \mathrm{~B}_{56} \mathrm{E}_{91}$ (the subscripts refer to the average degree

${ }^{\dagger}$ To whom correspondence should be addressed (Fax: +86-571-87952400, E-mail: xujt@zju.edu.cn). 
Table I. Characteristics of $\mathrm{B}_{28} \mathrm{E}_{182} \mathrm{~B}_{28}$ and $\mathrm{E}_{91} \mathrm{~B}_{56} \mathrm{E}_{91}$

\begin{tabular}{ccccr}
\hline Samples & $\begin{array}{c}M_{\mathrm{n}} \\
(\mathrm{g} / \mathrm{mol})\end{array}$ & $\phi_{\mathrm{E}}{ }^{a}$ & $\begin{array}{c}\text { Morphology } \\
\left(\text { at } 70{ }^{\circ} \mathrm{C}\right)\end{array}$ & $\begin{array}{r}T_{\mathrm{ODT}} \\
\left({ }^{\circ} \mathrm{C}\right)\end{array}$ \\
\hline $\mathrm{B}_{28} \mathrm{E}_{182} \mathrm{~B}_{28}$ & 12000 & 0.632 & lamellar & 83 \\
$\mathrm{E}_{91} \mathrm{~B}_{56} \mathrm{E}_{91}$ & 12000 & 0.632 & lamellar & 139 \\
\hline
\end{tabular}

${ }^{\mathrm{a}}$ volume fraction of the oxyethylene block at $70^{\circ} \mathrm{C}$.

of polymerization) were described elsewhere. ${ }^{4}$ $\mathrm{B}_{28} \mathrm{E}_{182} \mathrm{~B}_{28}$ has a molecular weight distribution (MWD) of $M_{\mathrm{w}} / M_{\mathrm{n}}<1.05$ and $\mathrm{E}_{91} \mathrm{~B}_{56} \mathrm{E}_{91}$ has a slightly broader MWD $\left(M_{\mathrm{w}} / M_{\mathrm{n}}<1.20\right)$. Some basic characteristics of these two triblock copolymers are listed in Table I.

\section{Differential Scanning Calorimetry (DSC) Experiments}

The non-isothermal and isothermal crystallization experiments were carried out on a PerkinElmer Pyris-1 calorimeter. Samples of the copolymer were sealed with aluminum pans and were heated to $70^{\circ} \mathrm{C}$, held for $5 \mathrm{~min}$. In non-isothermal crystallization the melts of the blends were cooled down to crystallize at prescribed rates. In isothermal crystallization the melts were cooled to crystallization temperature at a rate of $100^{\circ} \mathrm{C} / \mathrm{min}$ and held until crystallization was completed. Both the heat flow vs. time and heat flow $v s$. temperature profiles were simultaneously recorded. The isothermal crystallization kinetics of polymer was analyzed using Avrami equation: ${ }^{10}$

$$
1-X(t)=\frac{\Delta H_{t=\infty}^{\mathrm{c}}-\Delta H_{t}^{\mathrm{c}}}{\Delta H_{t=\infty}^{\mathrm{c}}-\Delta H_{t=0}^{\mathrm{c}}}=\exp \left(-k t^{n}\right)
$$

Where $X(t)$ is the relative crystallinity at time $t$, $\Delta H_{t=\infty}^{\mathrm{c}}$ and $\Delta H_{t}^{\mathrm{c}}$ are the crystallization enthalpies on complete crystallization and after time $t$. The time when the set crystallization temperature was reached was chosen as $t_{0}$. Therefore, we have:

$$
\log [-\ln (1-X(t))]=\log k+n \log t
$$

The crystallization rate constant $k$ and Avrami exponent $n$ can be determined from the intercept and slope in the plot of $\log [-\ln (1-X(t))] v s . \log (t)$. The data in induction time were omitted in the Avrami plots.

\section{Time-Resolved Small Angle X-Ray Scattering (SAXS)}

The simultaneous time-resolved SAXS/DSC experiments were carried out on beamline 8.2 of the SRS at the Daresbury, Warrington, U.K. The structures in the melt were measured after the samples were held at $70^{\circ} \mathrm{C}$ for $5 \mathrm{~min}$. The structures in the solid state were measured at $20^{\circ} \mathrm{C}$ after the samples were cooled from $70^{\circ} \mathrm{C}$ at a rate of $10^{\circ} \mathrm{C} / \mathrm{min}$. The temperatures were controlled by a Linkam DSC and were calibrated with standard substances. Details of the instrument and data processing are described elsewhere. ${ }^{1,2}$

\section{Polarized Optical Microscopy}

Polarized optical microscopy experiments were conducted on an Olympus BX50 microscope connected to a Panasonic NV-HD660 video recorder. Samples with $\sim 1 \mu \mathrm{m}$ thickness were heated to $70^{\circ} \mathrm{C}$ and held for 5 min using a Linkam DSC equipped with a liquid $\mathrm{N}_{2}$ cooling system. Subsequently the samples were cooled at a rate of $5{ }^{\circ} \mathrm{C} / \mathrm{min}$. The texture of the triblock copolymers during crystallization was recorded at an interval of $5 \mathrm{~s}$.

\section{RESULTS AND DISCUSSION}

\section{Non-isothermal Crystallization}

The non-isothermal crystallization curves of $\mathrm{B}_{28} \mathrm{E}_{182} \mathrm{~B}_{28}$ and $\mathrm{E}_{91} \mathrm{~B}_{56} \mathrm{E}_{91}$ at different cooling rates are shown in Figure 1(a) and (b), respectively. One can see that there is only a very small difference in crystallization temperature between $\mathrm{B}_{28} \mathrm{E}_{182} \mathrm{~B}_{28}$ and $\mathrm{E}_{91} \mathrm{~B}_{56} \mathrm{E}_{91}$ at the cooling rate of $2{ }^{\circ} \mathrm{C} / \mathrm{min}$. Considering the accuracy of DSC, we can say that $\mathrm{B}_{28} \mathrm{E}_{182} \mathrm{~B}_{28}$ and $\mathrm{E}_{91} \mathrm{~B}_{56} \mathrm{E}_{91}$ have similar crystallization temperatures at such a cooling rate. However, $\mathrm{B}_{28} \mathrm{E}_{182} \mathrm{~B}_{28}$ has a higher crystallization temperature than $\mathrm{E}_{91} \mathrm{~B}_{56} \mathrm{E}_{91}$ at faster cooling rates, showing that crystallization of $\mathrm{E}_{91} \mathrm{~B}_{56} \mathrm{E}_{91}$ is retarded at faster cooling rates. The melting DSC traces of $\mathrm{B}_{28} \mathrm{E}_{182} \mathrm{~B}_{28}$ and $\mathrm{E}_{91} \mathrm{~B}_{56} \mathrm{E}_{91}$ after non-isothermal crystallization are illustrated in Figure 2(a) and (b), respectively. In contrast to crystallization temperature, the melting temperatures of these two triblock copolymers are similar at all cooling rates applied.

\section{SAXS Result}

The Lorentzian-corrected SAXS profiles of $\mathrm{B}_{28} \mathrm{E}_{182} \mathrm{~B}_{28}$ and $\mathrm{E}_{91} \mathrm{~B}_{56} \mathrm{E}_{91}$ in the melt and in the solid state are shown in Figure 3. It is observed that both triblock copolymers have lamellar morphology in the melt and in the solid state, as evidenced by the positions of the higher order peaks at $q=2 q^{*}$ and $q=3 q^{*}$ (where $q$ is the position of the first order peak.). The higher order peaks in $\mathrm{B}_{28} \mathrm{E}_{182} \mathrm{~B}_{28}$ are not obvious, but appear after shearing and the lamellar morphology is confirmed (not shown here). We also notice that the SAXS peaks of $\mathrm{E}_{91} \mathrm{~B}_{56} \mathrm{E}_{91}$ are quite broad in both the melt and the solid state. This may result from some impurities of $\mathrm{E}_{91} \mathrm{~B}_{28}$ in this triblock block copolymer, since $\mathrm{E}_{91} \mathrm{~B}_{56} \mathrm{E}_{91}$ is synthesized by coupling $\mathrm{E}_{91} \mathrm{~B}_{28}$, and the broad SAXS peak is a common phenomenon in all $\mathrm{E}_{\mathrm{m} / 2} \mathrm{~B}_{\mathrm{n}} \mathrm{E}_{\mathrm{m} / 2}$ triblock copolymers. The long period $L$, which is the sum of the thickness of the B domain and the thickness of the E domain, can be obtained by $L=2 \pi / q^{*}$. It is found that the long periods in the melt are $123 \AA$ and $117 \AA$, respectively, for $\mathrm{E}_{91} \mathrm{~B}_{56} \mathrm{E}_{91}$ and $\mathrm{B}_{28} \mathrm{E}_{182} \mathrm{~B}_{28}$, but they 


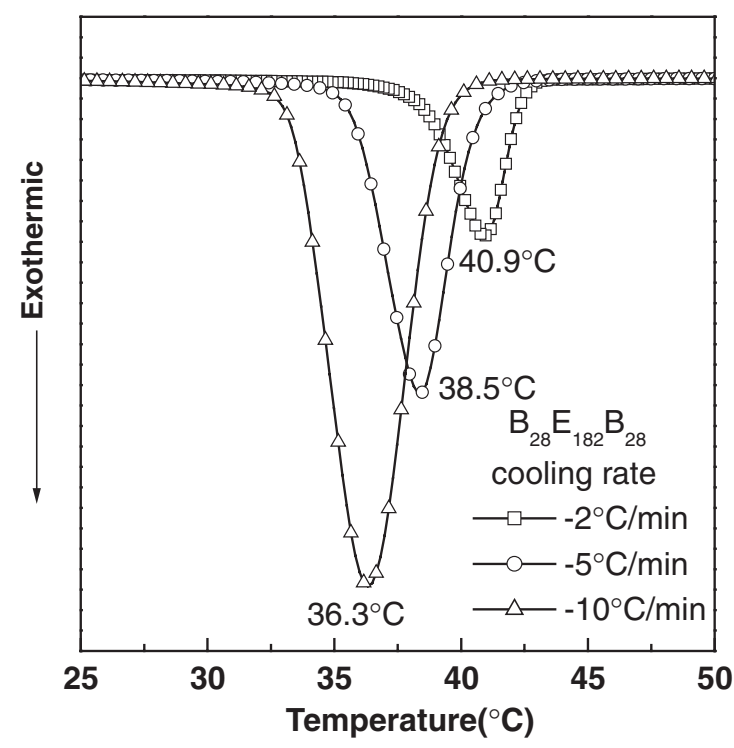

(a)

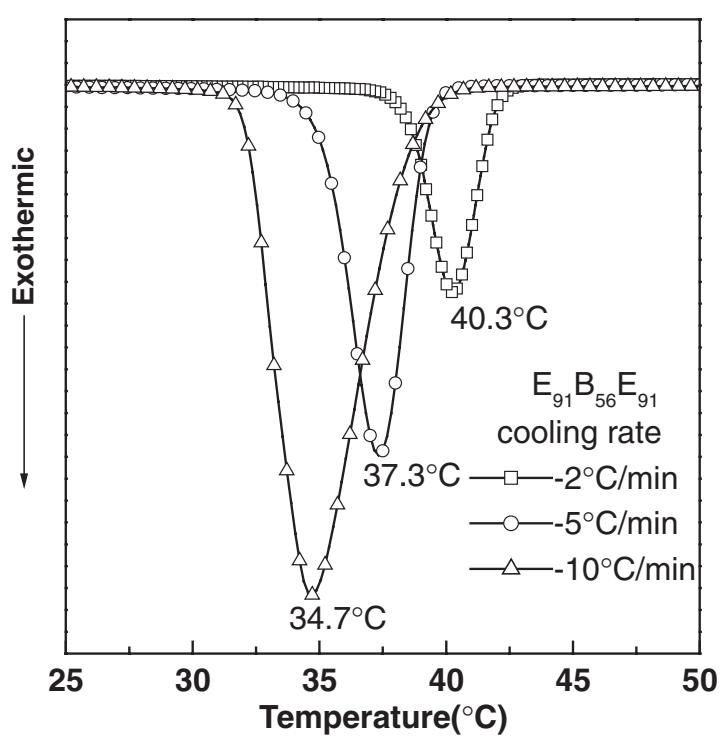

(b)

Figure 1. Crystallization DSC curves of (a) $\mathrm{B}_{28} \mathrm{E}_{182} \mathrm{~B}_{28}$ and (b) $\mathrm{E}_{91} \mathrm{~B}_{56} \mathrm{E}_{91}$ at different cooling rates.

become $164 \AA$ and $160 \AA$ after crystallization. Considering experimental errors, we can say that these two triblock copolymers have the same long period both in the melt and in the solid state. ${ }^{4}$ Previous studies on the solid structures of oxyethylene/oxybutylene diblock and triblock copolymers preferred to the conclusion that the crystal lamellar thickness of the E block is parallel to the "long period" direction. $., 11,12$ There are two possibilities for the structure of the E domains. Firstly, the E domains may consist of crystalline $\mathrm{E}$ layer and amorphous $\mathrm{E}$ layer, and the lamellar thickness of the $\mathrm{E}$ crystals, $L_{\mathrm{c}}$, is calculated by:

$$
L_{\mathrm{c}}=L \times \phi_{\mathrm{E}} \times X_{\mathrm{c}}
$$

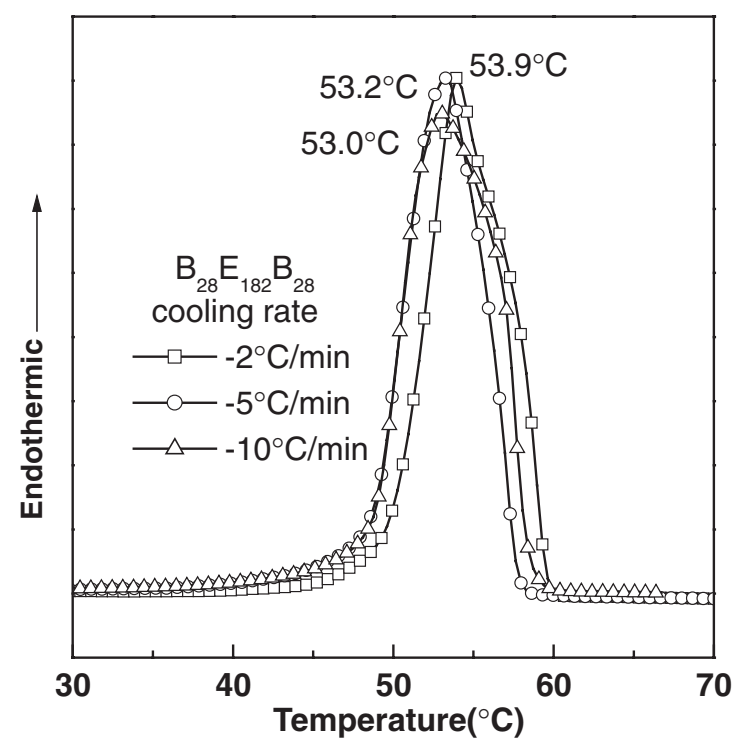

(a)

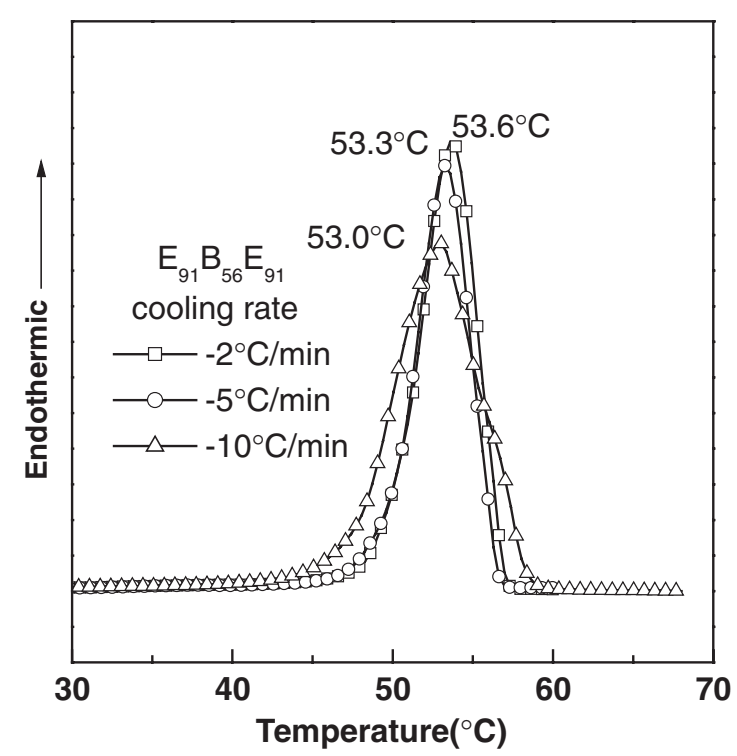

(b)

Figure 2. Melting DSC curves of (a) $\mathrm{B}_{28} \mathrm{E}_{182} \mathrm{~B}_{28}$ and (b) $\mathrm{E}_{91} \mathrm{~B}_{56} \mathrm{E}_{91}$ after non-isothermal crystallization.

where $\phi_{\mathrm{E}}$ and $X_{\mathrm{c}}$ are the volume fraction and crystallinity of the E block, respectively. Crystallinity of the E block can be obtained from the fusion enthalpy in DSC experiments, which is 0.880 and 0.875 for $\mathrm{B}_{28} \mathrm{E}_{182} \mathrm{~B}_{28}$ and $\mathrm{E}_{91} \mathrm{~B}_{56} \mathrm{E}_{91}$, respectively. Alternatively, the $\mathrm{E}$ domains may also consist of crystalline $\mathrm{E}$ layer-amorphous E layer-crystalline E layer. In this case, $L_{\mathrm{c}}$ is:

$$
L_{\mathrm{c}}=L \times \phi_{\mathrm{E}} \times X_{\mathrm{c}} / 2
$$

It is difficult to determine which situation is the real structure of the E domain only based on SAXS result. However, the same melting temperatures of $\mathrm{B}_{28} \mathrm{E}_{182}$ $\mathrm{B}_{28}$ and $\mathrm{E}_{91} \mathrm{~B}_{56} \mathrm{E}_{91}$ show that the number of chain 


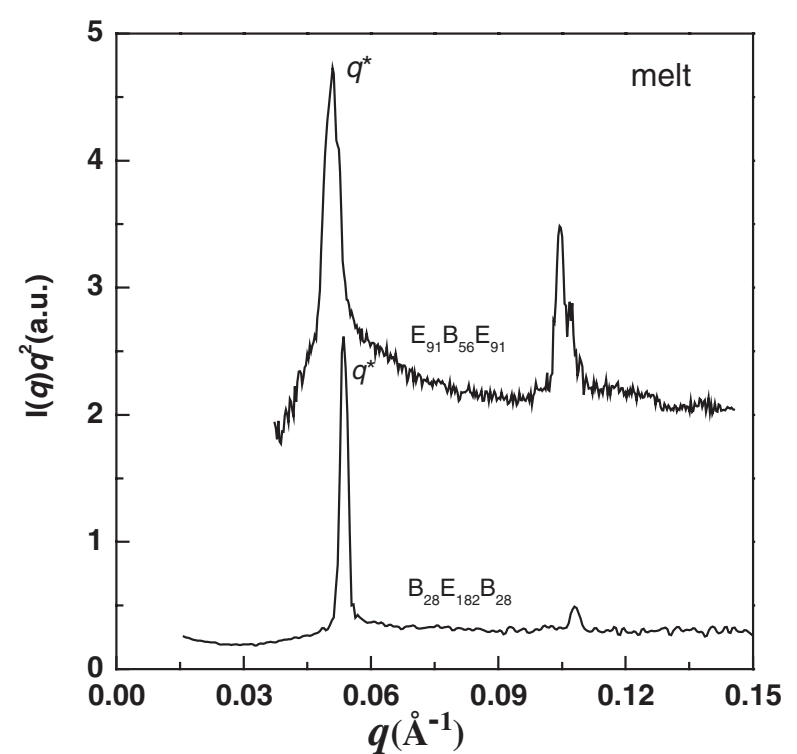

(a)

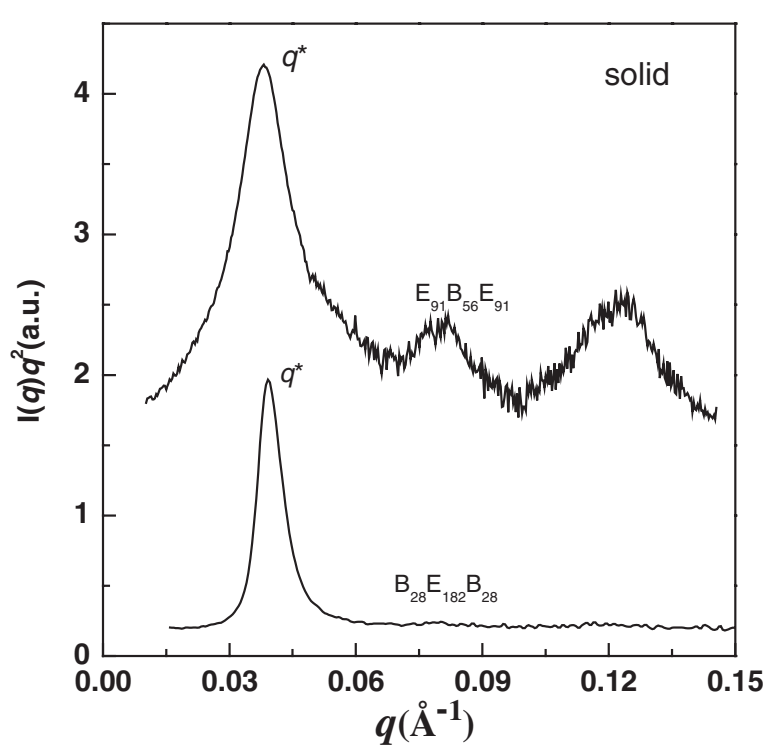

(b)

Figure 3. Lorentzian-corrected SAXS pofiles of $\mathrm{B}_{28} \mathrm{E}_{182} \mathrm{~B}_{28}$ and $\mathrm{E}_{91} \mathrm{~B}_{56} \mathrm{E}_{91}$ (a) in the melt $\left(70^{\circ} \mathrm{C}\right)$ and (b) in the solid state $\left(20^{\circ} \mathrm{C}\right)$. The solid samples were obtained by cooling the molten samples from $70^{\circ} \mathrm{C}$ to $20^{\circ} \mathrm{C}$ at a rate of $10^{\circ} \mathrm{C} / \mathrm{min}$. The data of $\mathrm{E}_{91} \mathrm{~B}_{56} \mathrm{E}_{91}$ are shifted by 1.5 .

folding in $\mathrm{B}_{28} \mathrm{E}_{182} \mathrm{~B}_{28}$ is twice that in $\mathrm{E}_{91} \mathrm{~B}_{56} \mathrm{E}_{91}$, which means that the $\mathrm{E}$ crystals in these two triblock copolymers have the same lamellar thickness. This is quite different from that in poly(ethylene oxide) (PEO) homopolymers. The PEO homopolymer with higher molecular weight usually forms thicker crystals and has higher melting temperature than the PEO homopolymer with lower molecular weight. Since the lamellar thickness of the PEO crystals is usually dependent on molecular weight in PEO homopolymer, the independence of the thickness of the crystals on chain length in $\mathrm{E}_{91} \mathrm{~B}_{56} \mathrm{E}_{91}$ and $\mathrm{B}_{28} \mathrm{E}_{182} \mathrm{~B}_{28}$ is probably due to the unique micro-phase separated morphology in block copolymers. After crystallization, the E block changes its conformation from random coil into folded chain and deformation also occurs in the amorphous B block, leading to the larger long period in the solid state than in the melt. ${ }^{11,13,14}$ The SAXS result reveals that $\mathrm{E}_{91} \mathrm{~B}_{56} \mathrm{E}_{91}$ and $\mathrm{B}_{28} \mathrm{E}_{182} \mathrm{~B}_{28}$ have the same morphology and long period both in the starting state (melt) and in the final state (solid), but the DSC experiments show that they have different crystallization rates.

\section{Isothermal Crystallization}

Figure 4 shows the Avrami plots of $\mathrm{B}_{28} \mathrm{E}_{182} \mathrm{~B}_{28}$ and $\mathrm{E}_{91} \mathrm{~B}_{56} \mathrm{E}_{91}$ crystallized at $40^{\circ} \mathrm{C}$ and $42^{\circ} \mathrm{C}$, respectively, and the obtained Avrami exponents $(n)$ and logarithmic crystallization rate constant $(\log k)$ are summarized in Table II. Since the $\mathrm{E}$ crystals in $\mathrm{B}_{28} \mathrm{E}_{182}$ $\mathrm{B}_{28}$ and $\mathrm{E}_{91} \mathrm{~B}_{56} \mathrm{E}_{91}$ have the same lamellar thickness in the solid state, the E crystals should have the same equilibrium melting temperatures as well. As a result, the degrees of supercooling are the same for these two triblock copolymers when they crystallize at the same temperatures and the data of crystallization kinetics

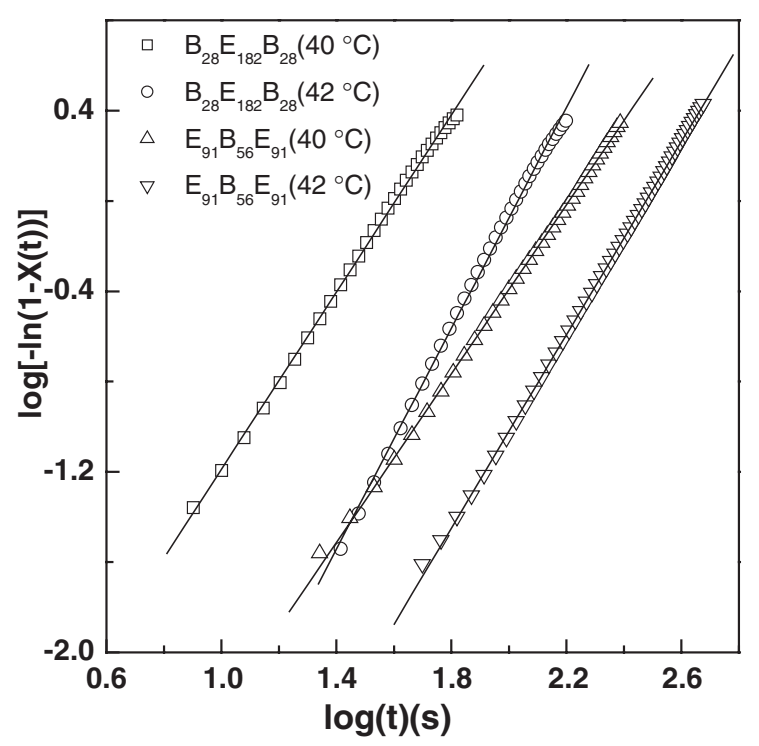

Figure 4. Avrami plots for $\mathrm{B}_{28} \mathrm{E}_{182} \mathrm{~B}_{28}$ and $\mathrm{E}_{91} \mathrm{~B}_{56} \mathrm{E}_{91}$ crystallized at two different temperatures.

Table II. Avrami exponents and crystallization rate constants

\begin{tabular}{cccc}
\hline Samples & $\begin{array}{c}T_{\mathrm{c}} \\
\left({ }^{\circ} \mathrm{C}\right)\end{array}$ & $n$ & $\begin{array}{c}\log k \\
\left(\mathrm{~s}^{-n}\right)\end{array}$ \\
\hline $\mathrm{B}_{28} \mathrm{E}_{182} \mathrm{~B}_{28}$ & 40 & 2.0 & -3.15 \\
& 42 & 2.4 & -4.96 \\
$\mathrm{E}_{91} \mathrm{~B}_{56} \mathrm{E}_{91}$ & 40 & 1.9 & -4.12 \\
& 42 & 2.1 & -5.30 \\
\hline
\end{tabular}




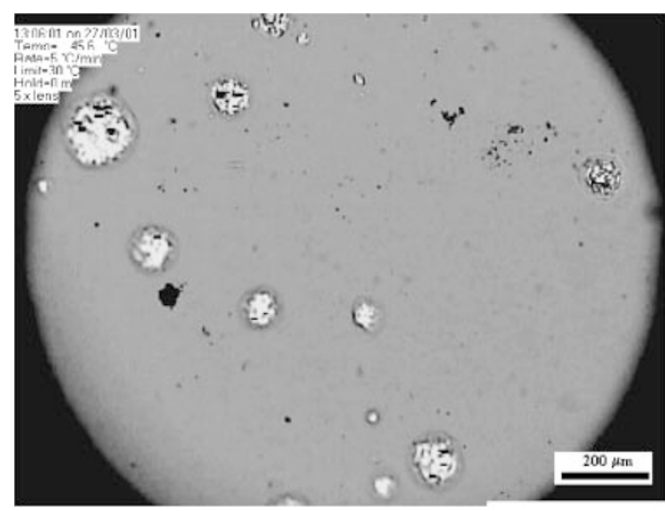

(a) $\mathrm{B}_{28} \mathrm{E}_{182} \mathrm{~B}_{28}$, at $45.6^{\circ} \mathrm{C}$

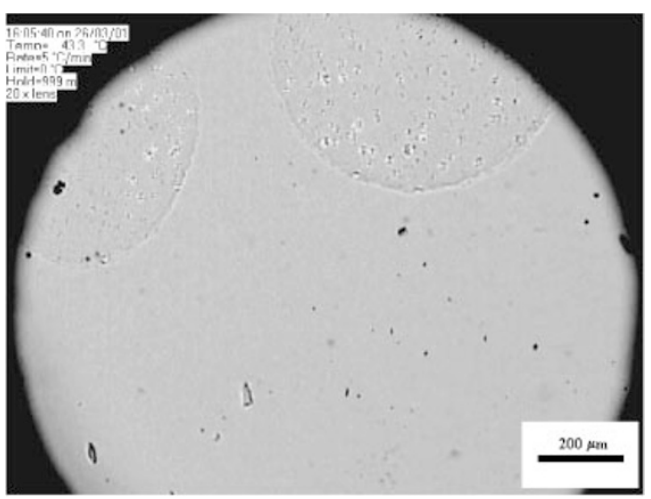

(c) $\mathrm{E}_{91} \mathrm{~B}_{56} \mathrm{E}_{91}$, at $43.3{ }^{\circ} \mathrm{C}$

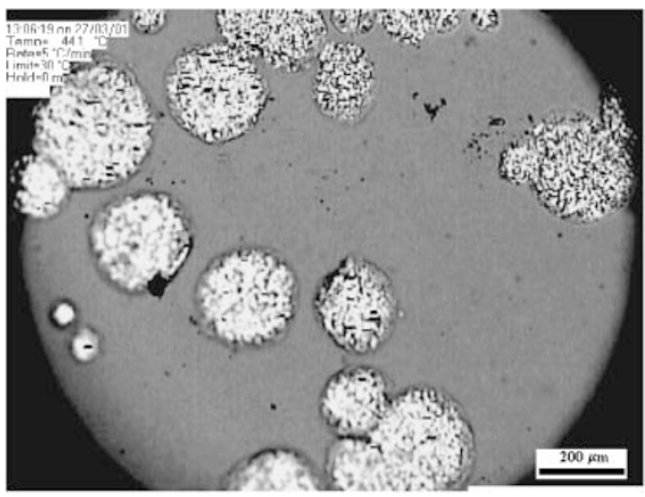

(b) $\mathrm{B}_{28} \mathrm{E}_{182} \mathrm{~B}_{28}$, at $44.1^{\circ} \mathrm{C}$

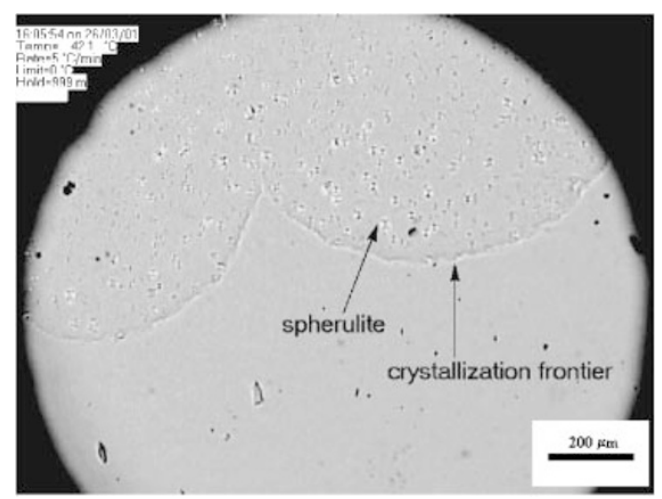

(d) $\mathrm{E}_{91} \mathrm{~B}_{56} \mathrm{E}_{91}$, at $42.1{ }^{\circ} \mathrm{C}$

Figure 5. Polarized optical micrographs of two block copolymers cooled from $70{ }^{\circ} \mathrm{C}$ at a rate of $5{ }^{\circ} \mathrm{C} / \mathrm{min} .(\mathrm{a}) \mathrm{B}_{28} \mathrm{E}_{182} \mathrm{~B}_{28}$, at $45.6{ }^{\circ} \mathrm{C}$, (b) $\mathrm{B}_{28} \mathrm{E}_{182} \mathrm{~B}_{28}$, at $44.1^{\circ} \mathrm{C}$, (c) $\mathrm{E}_{91} \mathrm{~B}_{56} \mathrm{E}_{91}$, at $43.3^{\circ} \mathrm{C}$, and (d) $\mathrm{E}_{91} \mathrm{~B}_{56} \mathrm{E}_{91}$, at $42.1^{\circ} \mathrm{C}$.

are comparable. It is observed that these two triblock copolymers have similar Avrami exponent around 2.0. However, the crystallization rate constants of $\mathrm{B}_{28} \mathrm{E}_{182} \mathrm{~B}_{28}$ and $\mathrm{E}_{91} \mathrm{~B}_{56} \mathrm{E}_{91}$ are quite different. The triblock copolymer with central crystallizable block, $\mathrm{B}_{28} \mathrm{E}_{182} \mathrm{~B}_{28}$, exhibits larger crystallization rate constant, showing that $\mathrm{B}_{28} \mathrm{E}_{182} \mathrm{~B}_{28}$ has faster crystallization rate. It is also noticed that the difference in crystallization rate constant becomes smaller at higher crystallization temperature.

\section{Polarized Optical Microscopy}

When $\mathrm{B}_{28} \mathrm{E}_{182} \mathrm{~B}_{28}$ and $\mathrm{E}_{91} \mathrm{~B}_{56} \mathrm{E}_{91}$ are cooled from $70{ }^{\circ} \mathrm{C}$ at a rate of $5^{\circ} \mathrm{C} / \mathrm{min}$, the textures of these two triblock copolymers are recorded with polarized optical microscopy. Typical textures are depicted in Figure 5. It is observed that spherulites without evident Maltese crosses are formed in $\mathrm{B}_{28} \mathrm{E}_{182} \mathrm{~B}_{28}$. $\mathrm{E}_{91} \mathrm{~B}_{56} \mathrm{E}_{91}$ also has macroscopic morphology of spherulites when crystallization is completed. There are two remarkable differences in the macroscopic morphology between $\mathrm{B}_{28} \mathrm{E}_{182} \mathrm{~B}_{28}$ and $\mathrm{E}_{91} \mathrm{~B}_{56} \mathrm{E}_{91}$. Firstly, the diameter of spherulites in $\mathrm{B}_{28} \mathrm{E}_{182} \mathrm{~B}_{28}$ is much larger than that of spherulites in $\mathrm{E}_{91} \mathrm{~B}_{56} \mathrm{E}_{91}$. The diam- eter of spherulites in $\mathrm{B}_{28} \mathrm{E}_{182} \mathrm{~B}_{28}$ after complete crystallization is $100-200 \mu \mathrm{m}$, while it is only about $20 \mu \mathrm{m}$ in $\mathrm{E}_{91} \mathrm{~B}_{56} \mathrm{E}_{91}$. The PEO homopolymers of different lengths usually exhibit different linear growth rates of spherulites but do not show so large a difference in the diameter of the final spherulites. As a result, the larger difference in diameter of spherulites between $\mathrm{B}_{28} \mathrm{E}_{182} \mathrm{~B}_{28}$ and $\mathrm{E}_{91} \mathrm{~B}_{56} \mathrm{E}_{91}$ is due to the different connection ways of the segments. Secondly, the frontier of crystallization zones and the frontier of spherulites are identical in $\mathrm{B}_{28} \mathrm{E}_{182} \mathrm{~B}_{28}$, and the crystallized zones spread over the whole block copolymer as the spherulites expand. In contrast, lots of tiny spherulites are formed within the crystallized zones during crystallization of $\mathrm{E}_{91} \mathrm{~B}_{56} \mathrm{E}_{91}$, showing the different frontiers of crystallization zones and spherulites. Such a phenomenon has not been reported previously. Generally, either only spherulites (like Figure 5(a)) or crystallized zones without formation of spherulites are observed in a semicrystalline block copolymer. ${ }^{15}$ The non-synchronous formation of crystallization zones and spherulites in $\mathrm{E}_{91} \mathrm{~B}_{56} \mathrm{E}_{91}$ implies that organization of lamellar crystals into spherulites is heavily retarded by the amorphous B block. With 
the progress of crystallization (i.e. with the decrease of temperature during non-isothermal crystallization), the main characteristics of the crystals for these two triblock copolymers remain the same. In $\mathrm{B}_{28} \mathrm{E}_{182} \mathrm{~B}_{28}$ the spherulites grow gradually until impingement of different spherulites occurs, while in $\mathrm{E}_{91} \mathrm{~B}_{56} \mathrm{E}_{91}$ the crystallization frontiers move towards gradually but the size of the spherulites inside the crystallized zones keeps unchanged.

The isothermal crystallization kinetics and polarized optical micrographs have revealed that crystallization rate of $\mathrm{E}_{91} \mathrm{~B}_{56} \mathrm{E}_{91}$ is slower than that of $\mathrm{B}_{28} \mathrm{E}_{182} \mathrm{~B}_{28}$, though they have the same long periods and melting temperatures. Such a result is out of our expectation, since it had been thought that $\mathrm{B}_{28} \mathrm{E}_{182} \mathrm{~B}_{28}$ with amorphous block at both ends of the crystallizable E block should have lower mobility and thus slower crystallization rate. The present work shows that the amorphous blocks connected in fact do not retard crystallization of the central block seriously. The unexpected result can be explained by the conformational change of the amorphous block during crystallization. In the ordered melt, both blocks have conformation of random coil. With the progress of crystallization, chain folding takes place for the crystallizable block and the E block becomes more stretched. As a result, the interface area occupied by per amorphous block is reduced, and the B block adjusts its conformation accordingly, leading to deformation of the amorphous block to some extent. ${ }^{11,13,14}$ In $\mathrm{E}_{91} \mathrm{~B}_{56} \mathrm{E}_{91}$ both ends of the amorphous B block are immobilized at the interface and the conformational re-arrangement proceeds very slowly. Crystallization of the $\mathrm{E}$ block and conformational change of the $\mathrm{B}$ block proceed simultaneously and affect each other, thus crystallization of the $\mathrm{E}$ block is retarded by the slower conformational re-arrangement of the $\mathrm{B}$ block in $\mathrm{E}_{91} \mathrm{~B}_{56} \mathrm{E}_{91}$. In contrast, in $\mathrm{B}_{28} \mathrm{E}_{182} \mathrm{~B}_{28}$ only one of the ends of the amorphous B block is located at interface and the amorphous block can change its conformation easily. Above explanation still needs the confirmation of the simulation of molecular dynamics, which is our further work. At slower cooling rate in non-isothermal crystallization and higher crystallization temperature in isothermal crystallization, the crystallization rate of the E block is also very slow, which is comparable with the rate of conformational re-arrangement of the $\mathrm{B}$ block, and thus $\mathrm{E}_{91} \mathrm{~B}_{56} \mathrm{E}_{91}$ and $\mathrm{B}_{28} \mathrm{E}_{182} \mathrm{~B}_{28}$ shows smaller differences in crystallization temperature and in crystallization constant rate. Therefore, the mobility of the E block in $\mathrm{E}_{91} \mathrm{~B}_{56} \mathrm{E}_{91}$ is only partially reduced and is not so low that spherulites cannot be formed. The intermediate mobility of the $\mathrm{E}$ block in $\mathrm{E}_{91} \mathrm{~B}_{56} \mathrm{E}_{91}$ is the reason why the unique macroscopic morphology in Figure 5(c) and (d) is formed. It should also be noted that the B block just reduces the crystallization rate of the $\mathrm{E}$ block, but does not affect the final structure of in the solid state, such as long period and lamellar thickness of the $\mathrm{E}$ crystals.

\section{CONCLUSIONS}

The results show that $\mathrm{E}_{91} \mathrm{~B}_{56} \mathrm{E}_{91}$ and $\mathrm{B}_{28} \mathrm{E}_{182} \mathrm{~B}_{28}$ have similar crystallization temperatures, melting temperatures and long periods. However, The crystallization temperature of $\mathrm{E}_{91} \mathrm{~B}_{56} \mathrm{E}_{91}$ is more easily affected by the cooling rate and $\mathrm{E}_{91} \mathrm{~B}_{56} \mathrm{E}_{91}$ has lower crystallization temperature at higher cooling rate. $\mathrm{E}_{91} \mathrm{~B}_{56} \mathrm{E}_{91}$ also exhibits slower crystallization rate than $\mathrm{B}_{28} \mathrm{E}_{182} \mathrm{~B}_{28}$, as revealed by isothermal crystallization kinetics and polarized optical microscopy. A particular macroscopic morphology that the frontier of crystallization zones and that of spherulites are mutually different is observed in $\mathrm{E}_{91} \mathrm{~B}_{56} \mathrm{E}_{91}$. The slower crystallization rate and poorer ability of organization into spherulite of $\mathrm{E}_{91} \mathrm{~B}_{56} \mathrm{E}_{91}$ are attributed to the difficulty in conformational change of the amorphous $\mathrm{B}$ block in which both ends are immobilized at the interface.

Acknowledgment. Prof. C. Booth in University of Manchester, U.K. and Prof. A. J. Ryan in The University of Sheffield, U.K. are greatly acknowledged for providing the triblock copolymers and beamtime. This project was supported by National Natural Science Foundation of China (20374046) and by the Excellent Young Teachers Program of MOE, P. R. C.

\section{REFERENCES}

1. C. Chaibundit, W. Mingvanish, S. C. Turner, S. M. Mai, J. P. A. Fairclough, A. J. Ryan, M. W. Matsen, and C. Booth, Macromol. Rapid Commun., 21, 964 (2000).

2. S. M. Mai, W. Mingvanish, S. C. Turner, C. Chaibundit, J. P. A. Fairclough, F. Heatley, M. W. Matsen, A. J. Ryan, and C. Booth, Macromolecules, 33, 5124 (2000).

3. M. W. Matsen and R. B. Thompson, J. Chem. Phys., 111, 7139 (1999).

4. A. J. Ryan, S. M. Mai, J. P. A. Fairclough, I. W. Hamley, and C. Booth, Phys. Chem. Chem. Phys., 3, 2961 (2001).

5. J. D. Vavasour and M. D. Whitmore, Macromolecules, 25, 5477 (1992).

6. J. D. Vavasour and M. D. Whitmore, Macromolecules, 26, 7070 (1993).

7. I. W. Hamley, "The Physics of Block Copolymers," Oxford University Press, New York, N.Y., 1998.

8. C. Booth and D. Attwood, Macromol. Rapid Commun., 21, 501 (2000).

9. C. Chaibundit, W. Mingvanish, C. Booth, S. M. Mai, S. C. Turner, J. P. A. Fairclough, A. J. Ryan, and P. Pissis, Mac- 
romolecules, 35, 4838 (2002).

10. M. Avrami, J. Chem. Phys., 7, 1103 (1939).

11. A. J. Ryan, J. P. A. Fairclough, I. W. Hamley, S. M. Mai, and C. Booth, Macromolecules, 30, 1723 (1997).

12. S. M. Mai, J. P. A. Fairclough, K. Viras, P. A. Gorry, I. W. Hamley, A. J. Ryan, and C. Booth, Macromolecules, 30, 8392 (1997).
13. E. A. DiMarzio, C. M. Guttman, and J. D. Hoffmann, Macromolecules, 13, 1194 (1980).

14. M. D. Whitmore and J. Noolandi, Makromol. Chem., Macromol. Symp., 16, 235 (1988).

15. J. T. Xu, S. C. Turner, J. P. A. Fairclough, S. M. Mai, A. J. Ryan, C. Chaibundit, and C. Booth, Macromolecules, 35, 3614 (2002). 